\title{
Sexual Behavior, Function and Satisfaction in Headache Associated with Sexual Activity: A Systematic Review of Literature
}

\author{
Wei-Hsi Chen ${ }^{1,2 *}$, Mei-Yen Chu ${ }^{1,3}$, Yen-Chin Lin ${ }^{1}$ \\ ${ }^{1}$ Graduate School of Human Sexuality, Shu-Te University, Taiwan \\ ${ }^{2}$ Department of Neurology, Kaohsiung Chang Gung Memorial Hospital, College of Medicine, Chang Gung University, \\ Taiwan \\ ${ }^{3}$ Life Education Center, Chang Jung Senior High School, Taiwan \\ Email: ^brainhemostasis@yahoo.com
}

How to cite this paper: Chen, W.-H., Chu, M.-Y. and Lin, Y.-C. (2017) Sexual Behavior, Function and Satisfaction in Headache Associated with Sexual Activity: A Systematic Review of Literature. Advances in Sexual Medicine, 7, 65-81.

https://doi.org/10.4236/asm.2017.72005

Received: February 3, 2017

Accepted: March 28, 2017

Published: March 31, 2017

Copyright $\odot 2017$ by authors and Scientific Research Publishing Inc. This work is licensed under the Creative Commons Attribution International License (CC BY 4.0).

http://creativecommons.org/licenses/by/4.0/

\begin{abstract}
Introduction: Headache associated with sexual activity (HSA) is the painful event of head and neck precipitated only by sexual activity. The negative impact of sexuality is expected to be more severe in HSA patients and their partners than other headache disorder. In addition, social and cultural taboo may conceal sexual problem or hinder seeking counseling for sexual perplexity. A sufficient scientific evidence is therefore needed to clarify the misunderstanding and schedule appropriate education in clinical practice. Methods: A systematic review of literature was completed to elucidate the sexual behavior, function and satisfaction in HSA patients and their partners. Results: A total of 97 publications are eligible after careful screening. However, most of the studies focus on the etiopathogenesis or treatment. Sexual change was mentioned in 23 publications. Orgasmic headache is the most frequent type of HSA. The HSA occurs more frequent in dyadic than extradyadic sexual activity. Intercourse is the leading sexual act for HSA occurrence, following by masturbation. A few patients suffer HSA under specific sexual position, like kneeling, and trigger, such as cannabis. Pain can be rapidly ceased in half of patients when sexual activity was halted. Sexual function and sexual satisfaction may decrease in HSA patient and partner but improve after pain reversal. Conclusions: A shortage of sexuality data of HSA is documented in literature but that still clarifies the extradyadic and masturbatory effect on HSA occurrence. Nevertheless, HSA disturbs sexual function and satisfaction in patients and their partners. The pathogenesis of pain includes two components, the hypersympathetic status and exertional action. Therefore, physician can schedule their education and counseling for HSA according to these findings. Further investigation for sexual function and satisfaction is warranted.
\end{abstract}




\section{Keywords}

Headache, Sexual Activity, Masturbation, Intercourse, Pain

\section{Introduction}

Sexuality is fundamental for species generation in animal kingdom including human. However, sexual behavior, function and satisfaction, which determine the success and quality of sexuality, are negatively impacted by a variety of physiological and psychological problems, such as pain disorder [1]. Indeed, an impairment of sexual behavior, function and/or satisfaction has been revealed in patients with migraine and other headache disorders before [2] [3] and even after appropriate treatment [4]. On the other hand, a poor sexual quality may in turn detriment sexual behavior, function and/or satisfaction in both headacheoff or headache-on period [5] [6]. Sexuality and physiopsychological problem mutually interlude with each another and negative sexual impact may even continue after treatment or at headache-off period.

Headache associated with sexual activity (HSA) is a headache disorder which is precipitated by sexual activity only [7]. The relationship between headache and sexuality had been mentioned since the time of Hippocrates who suggested that HSA might be brought on by immoderate venery (or sexual indulgence) [8]. After the middle of this century, HSA is increasingly reported and its etiopathogenesis and treatment strategy have been widely discussed [9]. Since HSA is provoked merely by sexual activity and even specific act in some patients, it is expected to affect the sexuality more severe than other headache and pain disorder at headache-on and also headache-off period. In this study, we completed a systematic review literature covering the sexual behavior, function and satisfaction in patients with HSA and their partners to provide strategy for prevention or correction of sexual adversity in HSA patients and their partners.

\section{Materials and Methods}

The aim of this study was to elucidate the sexuality in HSA patients and their partners before and after treatment. A systematic literature review following the guidelines of Preferred Reporting Items for Systematic Reviews and Meta-Analyses (PRISMA) was performed [10]. The main interests were to find out the sexual history (premorbid sexual history like sexual orientation, preference, abuse and others) sexual behavior (partnering, pattern of sexual act, specificity of sexual act, trigger of pain, pain factor) and sexual function (libido, arousal and orgasm) in HSA patients, and sexual satisfaction in HSA patients and between with their partners.

\subsection{Literature Search}

A computer-based search of the literature was performed. However, there was 
no formal terminology before until HSA was popularly adoptedby medical professionals. Therefore, we used a list of keywords, which had beencoined for headache related to sexual activity in books, publications and medical society before [7] [9] [11] [12], for searching in scientific databases. These keywords were "headache associated with sexual activity", "coital headache", "coitus headache", "sexual headache", "preorgasmic headache", "orgasmic headache", "postorgasmic headache", "masturbatory headache", "masturbation headache", "benign sex headache", "benign vascular sexual headache", "coital cephalalgia", "intercourse headache", "orgasmic cephalalgia", "preorgasmic cephalalgia" or "postorgasmic cephalalgia". The English scientific databases included PROQUEST, PUBMED and Cochrane Database of Systematic Reviews. The Chinese scientific databases included the Taiwan Periodical Literature System (http://readopac.ncl.edu.tw/nclJournal) and Airiti Library (http://www.airitilibrary.com).

To obtain a large pool of data, all papers, books, proceedings, and abstracts that were published before December 2016 were considered in this study. Additionally, the references of each manuscript, book chapter and proceeding were further reviewed to ensure coverage of the literature.

\subsection{Data Extraction}

During the identification process in PRISMA [10], duplication, editorial comment, book comment, club meeting, reply from author, and non-human study were firstly excluded. In some investigating groups, they have been collecting HSA patients continuously and published their follow-up data in different time periods. Therefore, only the latest published clinical case-serial study was enrolled in this situation during the screening process in this study. Finally, publications were included only when they were case-controlled trial, observational study or case report study concerning for HSA in human. Each publication was then carefully read to search the content for any record of sexual history, sexual behavior, sexual function and sexual satisfaction in HSA patients and their partners as aforementioned interest.

\subsection{Classifications of Headache Associated with Sexual Activity}

Before formal classification was announced, HSA was practically classified into preorgasmic, orgasmic and postorgasmic headache basing on the time onset of pain. Since classification system was firstly used at 1988, the classification of HSA has changed three times till now (Table 1). In the first edition of International Classification of Headache Disorders (ICHD) at 1988, HSA was classified into three types, namely the dull, explosive and postural type that actually coincided with headache occurring before, during and after orgasm respectively [11]. In the second edition ICHD at 2004, HSA was classified into preorgasmic and orgasmic type. The postural type in previous classification was categorized into the "Headache attributed to spontaneous (or idiopathic) low cerebral spinal fluid pressure" [12]. In the third-beta version of ICHD at 2013, HSA was classified 
Table 1. The diagnostic criteria of headache associated with sexual activity proposed by the International Classification of Headache Disorder (ICHD).

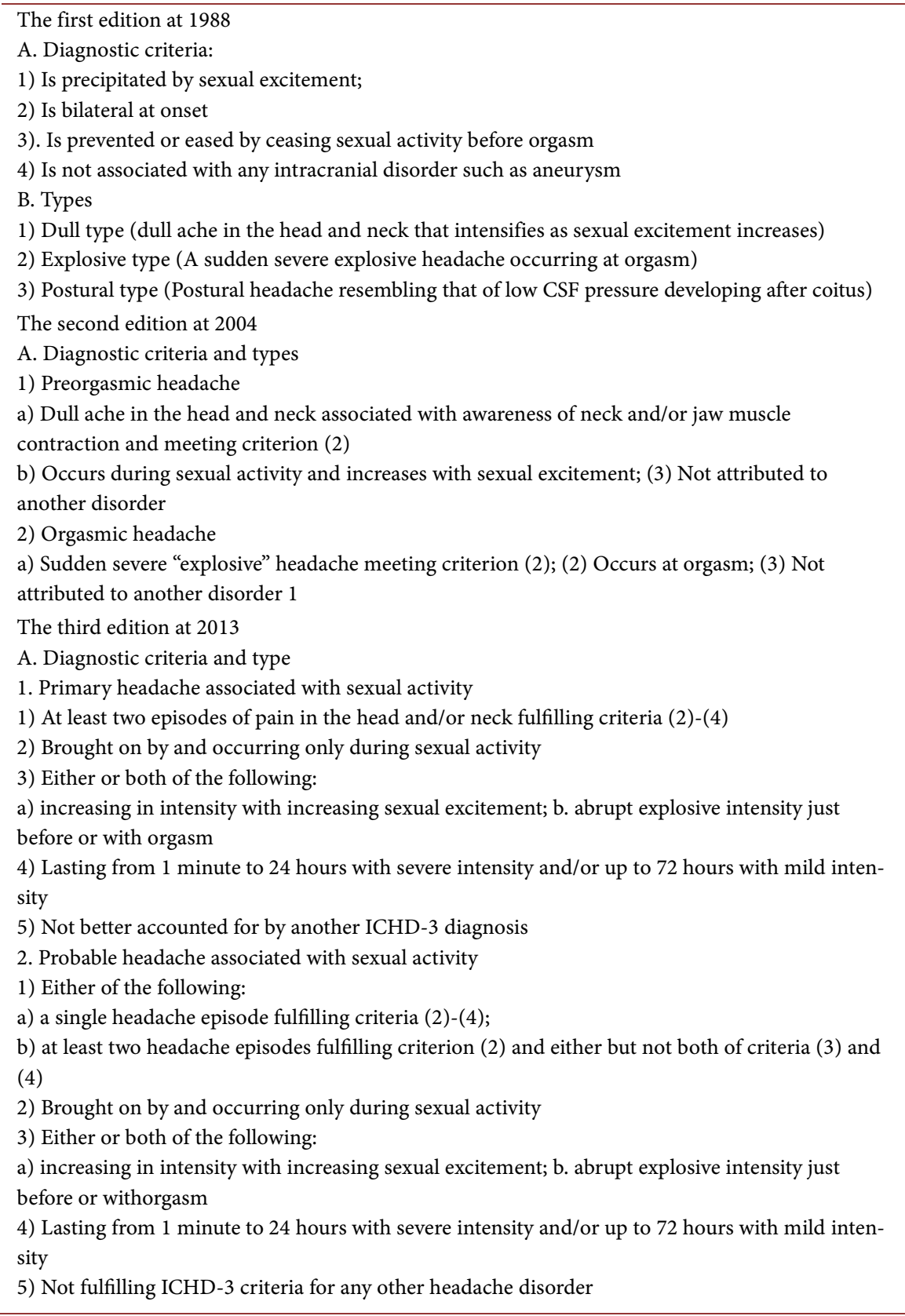

into definite and probable type only [7]. Since studies were published at different time periods and different classification systems were used, we therefore adopted the practical terminology of preorgasmic, orgasmic and postorgasmic headache which are still popularly used in many studies.

\section{Results}

After an exclusion of duplications and studies from the same groups and data, there were a total of 97 publications eligible, including 1 community observational study [13], 1 health checkup study [14], 20 clinical case-series studies 
(more than 5 patients in index report) [15]-[34], and 75 case-report studies (1 to 5 patients in index report) (Figure 1).

The lifetime prevalence of HSA was $1 \%$ in a community study [13]. The frequency of HSA was $0.28 \%$ in 1 health checkup study [14] whereas $6.06 \%$ in 1 emergency service-based study of any sexual complication events [15], and ranged from $0.28 \%$ to $1.63 \%$ (average being $0.36 \%$ ) in 5 clinic-based studies [16] [17] [18] [19] [20] (Table 2). Frese et al. [26] suggested the frequency of HSA to be $1 \%$ in their database but the total number of headache patients was unknown.

In those 97 eligible publications, the sexual history, behavior, functionor satisfaction compatible with our aforementioned interest were mentioned in only 23 publications [24] [25] [26] [29] [30] [31] [32] [35]-[50]. The main findings were described on the following paragraphs.

\subsection{Types of Headache}

\subsubsection{Type of Headache}

The type of headache was mentioned in 12 case-serial studies [20] [22]-[31] [33]. Two studies were excluded; type of headache was recorded in only 1 out of 6 patients in one study [24] and only orgasmic headache patients were enrolled in another study [29]. In the remaining 10 studies, the frequency of pre-orgasmic headache was $0 \%-57.9 \%$, orgasmic headache $26.3 \%-100 \%$, postorgasmic or postural headache $0 \%-19.2 \%$, mixed headache $0 \%-13.3 \%$, and uncertain headache $0 \%-4.8 \%$ of HSA patients. Therefore, the average frequency of preorgasmic, orgasmic, postorgasmic/postural, mixed and uncertain headache in these studies was $26.3 \%, 65.4 \%, 4.8 \%, 3.1 \%$ and $0.4 \%$, respectively. Orgasmic headache was the leading type of HSA and constituted two-third of all HSA events.

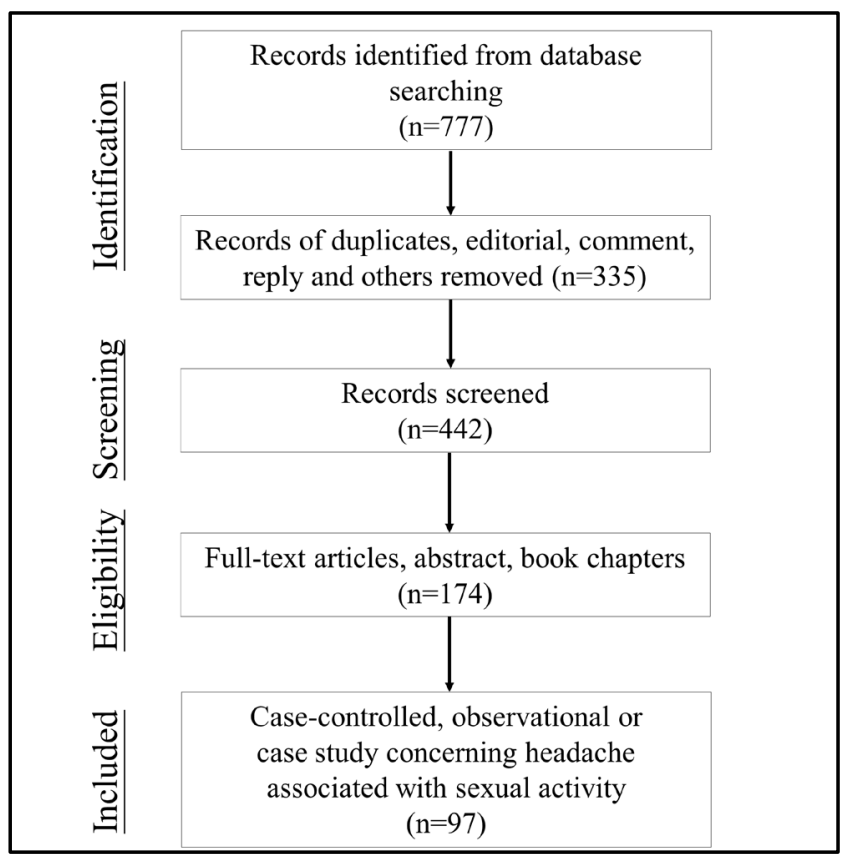

Figure 1. The selection process according to the PRISMA. 
Table 2. The frequency of headache associated with sexual activity (HSA) collected in literature.

\begin{tabular}{|c|c|c|c|c|c|c|c|}
\hline $\begin{array}{l}\text { Authors } \\
\text { Years }\end{array}$ & Region & $\begin{array}{c}\text { Case/total } \\
\text { number } \\
(\%)\end{array}$ & Source & $\begin{array}{l}\text { Male: } \\
\text { female }\end{array}$ & $\begin{array}{c}\text { Mean of } \\
\text { age (year) }\end{array}$ & $\begin{array}{c}\text { Typesof } \\
\text { headache }^{*}\end{array}$ & $\begin{array}{c}\text { Masturbatory } \\
\text { HSA (\%) }\end{array}$ \\
\hline $\begin{array}{l}\text { Hanashiro } \\
\text { et al., } 2015\end{array}$ & Japan & $\begin{array}{l}7 / 2546 \\
(0.28 \%)\end{array}$ & $\begin{array}{l}\text { Health } \\
\text { checkup }\end{array}$ & NR & NR & NR & NR \\
\hline $\begin{array}{l}\text { Pfortmueller } \\
\text { et al., } 2013\end{array}$ & Swiss & $\begin{array}{c}27 / 445 \\
(6.06 \%)\end{array}$ & $\begin{array}{c}\text { Emergency } \\
\text { service }\end{array}$ & $23: 4$ & $\begin{array}{c}\text { Men } 34 \\
\text { Women } 43\end{array}$ & NR & NR \\
\hline $\begin{array}{c}\text { Pascual et al., } \\
2008\end{array}$ & Spain & $\begin{array}{l}18 / 6412 \\
(0.28 \%)\end{array}$ & Clinic & $14: 4$ & 40 & NR & NR \\
\hline $\begin{array}{l}\text { Tuğba et al., } \\
\quad 2008\end{array}$ & Turkey & $\begin{array}{c}4 / 245 \\
(1.63 \%)\end{array}$ & Clinic & NR & NR & NR & NR \\
\hline Lamer, 2006 & $\begin{array}{l}\text { United } \\
\text { Kingdom }\end{array}$ & $\begin{array}{c}25 / 6,019 \\
(0.42 \%)\end{array}$ & Clinic & 19:6 & 41.6 & NR & NR \\
\hline Kraft, 1979 & Denmark & $\begin{array}{c}6 / 460 \\
(1.3 \%)\end{array}$ & Clinic & NR & NR & NR & NR \\
\hline $\begin{array}{c}\text { Nick \& } \\
\text { Bakouche, } \\
1960\end{array}$ & France & $\begin{array}{l}16 / 5800 \\
(0.28 \%)\end{array}$ & Clinic & NR & NR & $3 / 11 / 0 / 2$ & NR \\
\hline
\end{tabular}

NR: Not reported; *Types of headache: case number of preorgasmic/orgasmic/postorgasmic/mixed type of headache.

\subsubsection{Gender Difference}

The gender difference of HSA was mentioned in one case-serial study. In the series of Chakravarty [25], preorgasmic headache occurred in 14 males patients, whereas orgasmic headache in 1 male patient and 5 female patients.

\subsection{Sexual History}

In all studies, the sexual orientation, preference and abuse history were not mentioned.

\subsection{Sexual Behavior}

\subsubsection{Sexual Partner}

The identity of sexual partner in HSA attack was mentioned in 3 case-series studies. Chakravarty [25] reported all 15 men to have HSA during or after intercourse with their usual partners, whereas 2 women with their husband. No identity was mentioned in another 4 women. Frese et al. [26] reported 2.0\% of HSA patients to have HSA attack during intercourse with extramarital partner whereas $94 \%$ with marital or usual partners. The definition of usual partner was unclear in these studies. In the series of Porter and Jankovic [30], a 40-year-old man suffered orgasmic headache during intercourse with both the dyadic and extradyadic partners. In other case reports, sexual partner identity was not mentioned.

\subsubsection{Sexual Act}

Sexual act was mentioned in four case-serial studies. Lance [31] reported that sexual act was intercourse, masturbation and intercourse/masturbation in 18 (85.7\%), 1 (4.8\%) and 2 (9.5\%) patients, respectively. Silbert et al. [29] reported 
the sexual act to be intercourse only in their 45 patients. Chakravarty [25] reported the sexual act to be intercourse in $83.3 \%$ whereas masturbation in $16.7 \%$ of their patients, respectively. Frese et al. [26] reported 18 out of 51 patients to have HSA attack under masturbation. Intercourse was the most common sexual act in HSA, following by masturbation.

Regarding to masturbatory HSA, a total of 31 patients reported in literature [24] [25] [26] [31] [35]-[40]. These patients included both genders. Their headache was exclusively the orgasmic type. HSA was limited to masturbation alone in 8 patients, masturbation and intercourse in 22 patients, and uncertainty in 1 patient. Intracranial abnormality was found in only 2 of them; aneurysmal subarachnoid hemorrhage in 1 patient [35] and right middle cerebral artery spasm and posterior fossa arachnoid cyst in another 1 patient [39].

Foreplay [41] or pornography-associated HSA [42] was reported in 1 patient, respectively. The headache type was mixed pre-orgasmic and orgasmic type in the former whereas pre-orgasmic in the latter.

Arikanoglu et al. [43] and Dexter et al. [44] reported a total of two patients whose HSA was provoked by any sexual activity. However, the pattern of sexual act was not further mentioned.

Other sexual acts, such as anal sex, zoophilia, sadomasochism, swapping, causal sex, trade sex, orgy or other, were entirely not mentioned in any study.

\subsubsection{Sexual Position}

The position of specific sexual act for HSA was mentioned in three case-serial studies. In the series of Frese et al. [26], HSA occurred under specific act of intercourse in $5(8.4 \%)$ out of 51 patients, including kneeling position in 2, supine position in 2, and fellatio in 1 patient respectively. In the series of Valença et al. [24], a 44-year-old woman suffered HSA under masturbation or intercourse with her husband in standing position. In the series of Porter and Jankovic [30], a 40-year-old man suffered HSA in kneeling position.

\subsubsection{Trigger}

Trigger was mentioned in three case-serial studies and 1 case report. In the series of Lance [31], a patient suffered HSA from intercourses mainly after close successions. In the series of Paulson and Klawans [32], a 27-year-old woman suffered HSA for 4 months after contraceptive pill use. Her HSA did not recur after pill withdrawal. In the series of Silbert et al. [29], a 42-year-old man suffered his first time of HSA after returning from a prolonged posting. Alvaro et al. [45] described a 33-year-old man to have his first time of preorgasmic headache after cannabis use. Headache did not recur after cannabis was ceased. Otherwise, there was no report concerning for specific trigger, such as sex-promoting drug, in all other studies.

\subsubsection{Pain Factors}

The relationship of pain occurrence and sexual role was mentioned in three case-serial studies and 1 case report. Silbert et al. [29] reported that all their HSA patients suffered pain during undertaking the active role in intercourse. Frese et al. [29] reported a resolution of pain by passive role in 26 out of 51 patients 
(51\%). On the other hand, Lance [31] and Bandini et al. [46] separately reported 1 patient whose preorgasmic headache did not ameliorate after changing from active to passive role.

The relationship between the intensity of pain and magnitude of sexual excitement was mentioned in 3 case reports [37] [43] [47]. In these reports, a total of 3 patients stated that the intensity of pain correlated in parallel to the magnitude of sexual excitement during sexual activity.

The effect of cessation of sexual activity on pain was mentioned in one caseserial study and 4 case reports [41] [42] [43] [48]. Frese et al. [26] reported that 8 out of $11(72.7 \%)$ patients with preorgasmic headache and 12 out of $40(30 \%)$ patients with orgasmic headache achieved a decrease or a resolution of pain when they ceased sexual activity abruptly before pain increment. Immediate cessation of sexual activity rapidly ameliorated pain in another 3 patients [41] [42] [43] but showed uncertain benefit in another 1 patient [48].

\subsection{Sexual Function}

The sexual function of HSA patient was not mentioned in all studies, except one case report in that Chen et al. [49] described a man to have impotence during the headache-on period. The pain and impotence made this patient to avoid orgasm during intercourse committed with his wife who also suffered anorgasmia concurrently.

\subsection{Sexual satisfaction}

\subsubsection{Sexual Satisfaction}

Sexual satisfaction in HSA patient or partner was mentioned only in one case report. Chen et al. [49] reported the change of Golombok-Rust Inventory of Sexual Satisfaction in a 43-year-old man who suffered intercourse HSA. This man showed a high score for satisfaction, avoidance, infrequency and non-communication whereas his wife for dissatisfaction, infrequency and non-communication.

Porter and Jankovic [30] reported the partner of a 40-year-old HSA man to show high anxiety for index pain problem.

\subsubsection{Sexual Adjustment}

Sexual adjustment was not mentioned in all studies. In order to prevent HSA, 2 patients selected avoidance of sexual activity [43] [50].

\subsection{Sexuality after Treatment}

There was no study concerned for any change of sexual behavior, function or satisfaction after treatment or headache-off period except for one case report in that impotence, dissatisfaction, avoidance, infrequency and non-communication significantly subsided to baseline level in a man after index HSA was successfully abolished by renin antagonist [49].

\subsection{Summary of Literature Findings}

1) The lifetime prevalence of HSA was $1.0 \%$ in community population. The 
clinic-based frequency of HSA was $0.36 \%$. Orgasmic headache was the leading type of HSA.

2) HSA occurred more frequent in dyadic than extradyadic relationship, and intercourse than masturbation.

3) HSA was provoked with specific sexual position in $8.1 \%$ of patients. Active role of sexual act seemed to potentiate pain occurrence, whereas passive role decreased pain in half of patients. The intensity of pain was in parallel to the magnitude of sexual excitement in some patients. Rapid cessation of sexual activity before pain increment might prevent further pain ongoing, especially in preorgasmic headache.

4) Sexual function and sexual satisfaction might be disturbed in HSA patients and their partners but concerning data was insufficient.

5) No data was documented for sexual behavior, function or satisfaction after treatment with pain resolution.

\section{Discussion}

Our study is the first systematic review of sexuality in HSA patients. In contrast to an overwhelming data of etiopathogenesis and treatment method, a relative shortage of information concerning for sexual change in HSA is clearly revealed in this study. This discordance implicates an underestimation or neglect of sexual health care and concept within the clinically-based framework of health care. Since sexual health is an indispensable component of health care and well-being, it is better for promoting the quality of patient-centered care by increasing sexual knowledge and sensitivity in clinical training course.

Although laypersons consider that extradyadic relationship is risky, stressful and unhealthy, current findings interestingly show that HSA predominantly occurs under sexual activity with spouses or usual partners than extradyadic persons. Factually, extradyadic involvement is not uncommon in both modern western and eastern society, ranging from $50 \%-82 \%$ of men and $26 \%-70 \%$ of women [51]. It is estimated to be $25.0 \%$ of monogamous relationship in United States [52] and $15.2 \%$ of Chinese migrant workers [53]. Generally, the frequency is higher in men than women in both the western [54] and eastern countries [55]. If so, our results may be challenged invalid as HSA patients may selectively report committing intercourse only with spouses or usual partners but not extradyadic ones to protect their dyadic relationship. Indeed, sexuality is an embarrassing topic in consultation although patients generally hope to get more information about the impact of sexual activity on their health [56]. Nevertheless, these challenges are merely speculated unless more objective evidence can be raised to support them. Since pain and headache generally relate to acute or chronic stress and extradyadic involvement is considered stressful for health, it wonders if stress or its related change also involves with HSA in dyadic relationship.

Besides of sexually transmitted diseases, a higher frequency of cardiovascular events is recently found in extradyadic individuals [57], probably related to 
stress-mediated hypersympathetic vasoconstriction and cardiomyopathy [57]. In this study and previous HSA reports, there are four lines of evidence to support hypersympathetism in HSA. First, an outnumbered orgasmic type of headache is characterized in overall HSA patients [14] [15] [16], [26]-[34]. Second, intracranial vasospasm is occasionally found in primary and secondary HSA [22] [23] [24]. Third, Charavaty [25] reported a woman (Case E) who acknowledged her HSA occurred under a passionate sex with husband during shower. Fourth, propranolol and other sympatholytics favorably benefit for HSA [21]-[26] [29]. Taken together, we think that a higher frequency of HSA in dyadic relationship also results from, at least, hypersympathetic status. Our results do not encourage extradyadic relationship in HSA patients. Rather, health care providers should honestly inform that HSA can occur in both dyadic and extradyadic relationship and patients with HSA should modify their sexual relationship and daily living to avoid hypersympathetism, such as stress or concomitant drug or alcohol usage that frequently co-exists with extradyadic relationship.

In contrast to several hundred patients of intercourse HSA, there are only a total of 31 masturbatory HSA collected in this study [24] [25] [26] [31] [35][40]. In United States, the National Survey of Sexual Health and Behavior [58] has shown that the frequency of masturbation in alone or with partners ranges from $27.9 \%$ to $68.6 \%$ of men whereas approximately $20 \%$ of women in each age group in the past month. On average, masturbation is slightly more frequent than vaginal intercourse in men but vice versa in women. In Australia, the Second Australian Study of Health and Relationships [59] found that $51 \%$ of the men and $24 \%$ of women had masturbated in the past 1 month. Accordingly, a discordant frequency of intercourse and masturbatory HSA is obviously seen, especially in men. Since the majority of masturbatory HSA co-exists with intercourse HSA, reporteé may omit or overlook their masturbatory HSA upon consultation.

In contrast to intercourse, solo or partnered masturbation is to stimulate the genitalia to the point of orgasm with an essential autoerotic component. In this study, the masturbatory HSA exclusively occurs at orgasm [24] [25] [26] [31] [35]-[40] and is therefore suggested to share a hypersympathetic basis along with a different process for pain occurrence with intercourse HSA. Two findings may account for a relative lower frequency of masturbatory HSA. First, although masturbation and intercourse terminate to orgasm similarly, response to cardiovascular stress is different, however. The penile-vaginal intercourse benefits the blood pressure reactivity to stress but masturbation unfortunately reduces this beneficial effect [60] [61], suggesting that masturbation exposes individual to risk for hypersympathetic status. Second, a modest prevalence of exertional headache is seen in HSA [29] and a cessation of intercourse [25] [26] or masturbation [24] [25] [26] can abolish or attenuate the pain, Clearly, exertion during intercourse or masturbation is another factor crucial for HSA occurrence. Masturbation generates exertion less effort than intercourse and is reasonable to provoke HSA less frequent than intercourse. Therefore, exertion and hypersym- 
pathetism are likely two interacting but independent factors for pain occurrence in HSA, and account for different HSA occurrence between masturbation and intercourse.

Specific sexual position is mentioned for pain triggering in $8 \%$ of HSA patients, including supine, standing, kneeling or fellatio [26]. These positions are not compatible with the vertical change in postural or orthostatic HSA which results from cerebrospinal fluid leakage. Since specific act-associated HSA principally occurs during orgasm, it may relate to the disharmony of cerebrovascular tonicity regulation under exertion and hypersympathetic status during intercourse. Generally, cerebral blood flow progressively increases to compete with cerebral metabolic demand in exercise [62]. The sympathetic and vascular responses are modulated by a few factors, especially the position [63], carbon dioxide tension and lactate. In high-intensity exercise, the distribution of cerebral blood flow changes, that is, a decrease of blood flow in internal carotid artery whereas vice versa in external carotid artery to facilitate thermal regulation [64]. Although reporteé do not approve if the index specific act facilitates their orgasm more easier than other position, specific sexual act may provoke HSA through the dysregulation of sympathetic and vascular response unique to individually sexual consequence of metabolic change during intercourse.

Current available data find that sexual function is generally overlooked in HSA patients. Only an adult man who suffered impotence under HSA attack was reported [49]. Depression was not documented. Sexual dysfunction is not uncommon in patients with migraine and other headache disorders [65] [66]. Generally, sexual response cycle is consistently disturbed in female migraineurs [67] whereas mainly erectile dysfunction in male migraneurs [65] [68] [69]. Sexual dysfunction is related to depression but not the severity or disability of female migraineurs [67]. On the other hand, the risk factor is not determined in male migraineurs for sexual dysfunction [65]. Nevertheless, a parallel resolution of HSA after a correction of impotence and other sexual dysfunction in index patient strongly indicate a causal relationship between HSA and sexual dysfunction in man [49] similar to other headache disorder. An improvement of pain occurrence is the first step for sexual dysfunction in HSA patient but organic cause should also be cautioned.

Satisfaction is important for stabilizing bonding and pairing in couples. Although human can adjust oneself for stress in many acute and chronic conditions, dissatisfaction is still an unstable bomb for breaking relationship at any time during relationship. Regarding to HSA, sexual dissatisfaction is revealed in a HSA man and his spouse concurrently [49]. Sexual satisfaction, but not general dissatisfaction [2] is usually lower in migraineurs than migraineurs [2] [67], The prevalence of sexual dissatisfaction in migraineurs ranges from 30.4\% in Spanish [70] to $66.7 \%$ in Ghanaian [69]. Interestingly, sexual dissatisfaction continuously persists in some migraineurs even under appropriate treatment due to different causes, such as drug effect [70] or psychological factor [71]. Although sexual satisfaction significantly improves in index HSA patient after pain resolution [49], 
more data is warranted for making a more appropriate suggestion in clinical practice. Drug adversity should also be cautioned for sexual pharmacotoxicity in HSA patient.

The HSA is seemingly not a malignant pain disorder as pain spontaneously subsides in over two-third of sufferers [26]. In the remainders, presumptive and abortive treatment usually gives beneficiary effect. However, the sexual function is barely mentioned in HSA patient and spouse/partner under and after treatment. Limited data show that sexual function and sexual satisfaction improve to baseline level after pain subsided in a HSA man [49]. However, more evidence is needed for conclusion, especially in chronic HSA patient and their partner.

The main limitation in this study is that almost all of the HSA studies and reports focus only on the etiology, diagnosis and treatment. The sexuality of HSA patients and their partner is seriously overlooked. The data of sexual behavior, function and satisfaction before, under and after treatment is sparse. This neglect disadvantages for understanding the effect of HSA on the sexual well-being and relationship in HSA patients and partner and hinder to schedule counseling strategy for sexual complication in HSA.

Although sexual health care has been announced by the World Health Organization more than a decade ago, current study still discloses a shortage of sexuality concept in HSA care. In order to promote the sexuality concept and care in HSA and other conditions involving sexual complication, two educational ideas are suggested. First, sexual health education, including communication skill, should be scheduled in continuous medical program. Second, the quality of clinical case report or study should be improved. At least, the sexual identity, behavior, function and satisfaction must be mentioned. A formal template can be designed for this situation.

\section{Conclusion}

Misunderstanding and prejudice treat sexuality-related event non-scientifically and hostilely. This study cannot cover all aspects of sexuality for HSA but still provides scientific evidence to elucidate the sexual behavior, function and satisfaction in HSA patients and their partners. Orgasmic headache is the most frequent type of HSA. The HSA can occur in dyadic and extradyadic sexual activity. Intercourse is the leading sexual act for HSA occurrence, following by masturbation. A few patients suffer HSA under specific sexual position, like kneeling, and trigger, such as cannabis. Sexual function and sexual satisfaction may decrease in HSA patient and partner, and improve after pain reversal. The pathogenesis of pain is multifactorial and includes two components, the hypersympathetic status and exertional action. Therefore, physician can schedule their education and counseling for HSA according to these findings. Further investigation for sexual function and satisfaction is warranted.

\section{References}

[1] Kwanm K.S., Roberts, L.J. and Swalm, D.M. (2005) Sexual Dysfunction and Chronic 
Pain: The Role of Psychological Variables and Impact on Quality of Life. European Journal of Pain, 15, 643-652.

[2] Ifergane, G., Ben-Zion, I.Z., Plakht, Y., Regev, K. and Wirguin, I. (2008) Not Only Headache: Higher Degree of Sexual Pain Symptoms among Migraine Sufferers. Journal of Headache and Pain, 15, 113-117. https://doi.org/10.1007/s10194-008-0028-8

[3] Bestepe, E., Cabalar, M., Kucukgoncu, S., et al. (2011) Sexual Dysfunction in Women with Migraine versus Tension-Type Headaches: A Comparative Study. International Journal of Impotence Research, 15, 122-127. https://doi.org/10.1038/ijir.2011.16

[4] Nappi, R.E., Terreno, E., Tassorelli, C., et al. (2012) Sexual Function and Distress in Women Treated for Primary Headaches in a Tertiary University Center. Journal of Sexual Medicine, 15, 761-769. https://doi.org/10.1111/j.1743-6109.2011.02601.x

[5] Tugut, N., Golbasi, Z. and Bulbul, T. (2016) Quality of Sexual Life and Changes Occurring in Sexual Life of Women With High-Risk Pregnancy. Journal of Sex and Marital Therapy, 22, 1-10.

[6] Schouffoer, A.A., van der Marel, J., Ter Kuile, M.M., et al. (2009) Impaired Sexual Function in Women with Systemic Sclerosis: A Cross-Sectional Study. Arthritis and Rheumatism, 61, 1601-1608. https://doi.org/10.1002/art.24728

[7] Headache Classification Committee of the International Headache Society (IHS) (2013) The International Classification of Headache Disorders. 3rd Edition (beta version), Cephalalgia, 33, 629-808.

[8] Adams, F. (1886) The Genuine Works of Hippocrates. William Wood, New York.

[9] Wolff, H.G. (1963) Headache and Other Head Pain. 2nd Edition, Oxford University Press, New York.

[10] Moher, D., Liberati, A., Tetzlaff, J. Altman, D.G. and PRISMA Group (2009) Preferred Reporting Items for Systematic Reviews and Meta-Analyses: The PRISMA Statement. British Medical Journal, 339, b2535. https://doi.org/10.1136/bmj.b2535

[11] Headache Classification Committee of the International Headache Society (1988) Classification and Diagnostic Criteria for Headache Disorders, Cranial Neuralgias and Facial Pain. Cephalalgia, 8, 1-96.

[12] International Headache Society Classification Subcommittee (2004) The International Classification of Headache Disorders. 2nd Edition. Cephalalgia, 24, 1-160.

[13] Rasmussen, B.K. and Olesen, J. (1992) Symptomatic and Nonsymptomatic Headaches in a General Population. Neurology, 42, 1225-1231.

https://doi.org/10.1212/WNL.42.6.1225

[14] Hanashiro, S., Takazawa, T., Kawase, Y. and Ikeda, K. (2015) Prevalence and Clinical Hallmarks of Primary Exercise Headache in Middle-Aged Japanese on Health Check-Up. Internal Medicine, 54, 2577-2581. https://doi.org/10.2169/internalmedicine.54.4926

[15] Pfortmueller, C.A., Schankath, A.C., Mordasini, P., et al. (2014) Radiological Findings of Sexual Intercourse Related Emergency Department Admissions: A First Overview. PLoS ONE, 9, e104170. https://doi.org/10.1371/journal.pone.0104170

[16] Pascual, J., González-Mandly, A., Martín, R. and Oterino, A. (2008) Headaches Precipitated by Cough, Prolonged Exercise or Sexual Activity: A Prospective Etiological and Clinical Study. Journal of Headache and Pain, 9, 259-266. https://doi.org/10.1007/s10194-008-0063-5

[17] Tuğba, T., Serap, U., Esra, O., Ozlem, C., Ufuk, E. and Levent, E. I. (2008) Features of Stabbing, Cough, Exertional and Sexual Headaches in a Turkish Population of 
Headache Patients. Journal of Clinical Neuroscience, 15, 774-777.

[18] Larner, A.J. (2006) Late Presentation of Primary Headache Associated with Sexual Activity: Is Non-Invasive Angiography Worthwhile? Journal of Headache and Pain, 7, 139-140. https://doi.org/10.1007/s10194-006-0297-Z

[19] Kraft, M. (1979) Benign Coital Cephalgia. Violent Headache Developing during Sexual Intercourse. Ugeskrift for Laeger, 141, 2454-2455

[20] Nick, J. and Bakouche, P. (1980) Les cephalees declenchees par l'acte sexual. Semaine des Hopitaux, 56, 621-628.

[21] Huang, Y., Zhu, K. and Chen, J. (2014) Primary Headache Associated with Sexual Activity: 15 New Cases and Therapeutic Outcomes. Chinese Medical Journal, 94, 1791-1794.

[22] Donnet, A., Valade, D., Houdart, E., et al. (2013) Primary Cough Headache, Primary Exertional Headache, and Primary Headache Associated with Sexual Activity: A Clinical and Radiological Study. Neuroradiology, 55, 297-305. https://doi.org/10.1007/s00234-012-1110-0

[23] Yeh, Y.C., Fuh, J.L., Chen, S.P. and Wang, S.J. (2010) Clinical Features, Imaging Findings and Outcomes of Headache Associated with Sexual Activity. Cephalalgia, 30, 1329-1335. https://doi.org/10.1177/0333102410364675

[24] Valença, M.M., Andrade-Valença, L.P., Bordini, C.A. and Speciali, J.G. (2008) Thunderclap Headache Attributed to Reversible Cerebral Vasoconstriction: View and Review. Journal of Headache and Pain, 9, 277-288. https://doi.org/10.1007/s10194-008-0054-6

[25] Chakravarty, A. (2006) Primary Headaches Associated with Sexual Activity-Some Observations in Indian Patients. Cephalalgia, 26, 202-207.

https://doi.org/10.1111/j.1468-2982.2005.01027.x

[26] Frese, A., Eikermann, A., Frese, K., Schwaag, S., Husstedt, I.W. and Evers, S. (2003) Headache Associated with Sexual Activity: Demography, Clinical Features, and Comorbidity. Neurology, 61, 796-800. https://doi.org/10.1212/01.WNL.0000083988.98336.A3

[27] Ekusheva, E.V. and Filatova, E.G. (2003) Headache Caused by Sexual Activity. Zhurnal Nevropatologii i Psikhiatrii Imeni S.S. Korsakova, 103, 21-25.

[28] Ostergaard, J.R. and Kraft, M. (1992) Benign Coital Headache. Cephalalgia, 12, 353 355. https://doi.org/10.1111/j.1468-2982.1992.00353.x

[29] Silbert, P.L., Edis, R.H., Stewart-Wynne, E.G. and Gubbay, S.S. (1991) Benign Vascular Headaches and Exertional Headache: Interrelationships and Long Term Prognosis. Journal of Neurology, Neurosurgery and Psychiatry, 54, 417-421. https://doi.org/10.1136/jnnp.54.5.417

[30] Porter, M. and Jankovic, J. (1981) Benign Coital Cephalalgia. Differential Diagnosis and Treatment. Archives of Neurology, 38, 710-712. https://doi.org/10.1001/archneur.1981.00510110070011

[31] Lance, J.W. (1976) Headaches Related to Sexual Activity. Journal of Neurology, Neurosurgery and Psychiatry, 39, 1226-1230. https://doi.org/10.1136/jnnp.39.12.1226

[32] Paulson, G.W. and Klawans, H.L. (1974) Benign Orgasmic Cephalgia. Headache, 13, 181-187. https://doi.org/10.1111/j.1526-4610.1974.hed1304181.x

[33] Martin, E.A. (1974) Headache during Sexual Intercourse (Coital Cephalalgia). A Report on Six Cases. Irish Journal of Medical Science, 143, 342-345. https://doi.org/10.1007/BF03004787

[34] Kríz, K. (1970) Coitus as a Factor in the Pathogenesis of Neurologic Complications. 
Ceskoslovenská Neurologie a Neurochirurgie, 33, 162-167

[35] Singh, D. and Jan, A. (2013) Subarachnoid Haemorrhage with Orgasmic Cephalgia. BMJ Case Reports, bcr2013008780. https://doi.org/10.1136/bcr-2013-008780

[36] Gelfand, A.A. and Goadsby, P.J. (2012) Primary Sex Headache in Adolescents. Pediatrics, 130, e439-e441. https://doi.org/10.1542/peds.2011-2624

[37] Evers, S., Peikert, A. and Frese, A. (2009) Sexual Headache in Young Adolescence: A Case Report. Headache, 49, 1234-1235. https://doi.org/10.1111/j.1526-4610.2009.01498.x

[38] Brilla, R. and Evers, S. (2005) A Patient with Orgasmic Headaches Converting to Concurrent Orgasmic and Benign Exertional Headaches. Cephalalgia, 25, 11821183. https://doi.org/10.1111/j.1468-2982.2005.00986.x

[39] Valença, M.M., Valença, L.P., Bordini, C.A., et al. (2004) Cerebral Vasospasm and Headache during Sexual Intercourse and Masturbatory Orgasms. Headache, 44, 244-248. https://doi.org/10.1111/j.1526-4610.2004.04054.x

[40] Vincent, F.M. (1982) Benign Masturbatory Cephalalgia. Archives of Neurology, 39, 673. https://doi.org/10.1001/archneur.1982.00510220071025

[41] Prakash, S. (2010) Hyper Insulinemia in an Hemicrania Continua Patient with Sexual Headache: Hypothesizing the Basis for This Unusual Association. Neurology India, 58, 642-644. https://doi.org/10.4103/0028-3886.68689

[42] Anand, K.S. and Dhikav, V. (2012) Headaches Induced by Pornography Use. Archives of Sexual Behavior, 41, 1077. https://doi.org/10.1007/s10508-012-9988-5

[43] Arikanoglu, A. and Uzar, E. (2011) Primary Headaches Associated with Sexual Activity Respond to Topiramate Therapy: A Case Report. Acta Neurologica Belgica, 111, 222-224.

[44] Dexter, S. (2010) Benign Coital Headache Relieved by Partner's Pregnancies with Implications for Future Treatment. BMJ Case Reports, bcr10.2009.2359.

[45] Alvaro, L.C., Iriondo, I. and Villaverde, F.J. (2002) Sexual Headache and Stroke in a Heavy Cannabis Smoker. Headache, 42, 224-226. https://doi.org/10.1046/j.1526-4610.2002.02056.x

[46] Bandini, F., Arena, E. and Mauro, G. (2012) Pre-Orgasmic Sexual Headache Responsive to Topiramate: A Case Report. Cephalalgia, 32, 797-798. https://doi.org/10.1177/0333102412452046

[47] Uterga, J.M., de Garay, M.A., de Luna, I.O. and Uribarri, J.B. (2009) Recurrent Coital Headache Associated with an Unruptured Carotid Saccular Aneurysm. Headache, 49, 1232-1233. https://doi.org/10.1111/j.1526-4610.2009.01479.x

[48] Hu, C.M., Lin, Y.J., Fan, Y.K., Chen, S.P. and Lai, T.H. (2010) Isolated Thunderclap Headache during Sex: Orgasmic Headache or Reversible Cerebral Vasoconstriction Syndrome? Journal of Clinical Neuroscience, 17, 1349-1351.

[49] Chen, W.H. (2015) Successful Reversal of Intractable Sexual Headache by Renin Antagonist. The Journal of Sexual Medicine, 12, 344.

[50] Gültekin, M. and Köseoğlu, E. (2012) Primary Headache Associated with Sexual Activity: Case Report and Review of the Literature. Turkish Journal of Neurology, 18, 77-81. https://doi.org/10.4274/Tnd.59354

[51] Vaughn, P. (2003) The Monogamy Myth: A Patiental Handbook for Recovering from Affairs. Newmarket Press, New York.

[52] Lehmiller, J.J. (2015) A Comparison of Sexual Health History and Practices among Monogamous and Consensually Nonmonogamous Sexual Partners. The Journal of Sexual Medicine, 12, 2022-2028. https://doi.org/10.1111/jsm.12987 
[53] Dai, W., Gao, J., Gong, J., et al. (2015) Sexual Behavior of Migrant Workers in Shanghai, China. BMC Public Health, 15, 1067. https://doi.org/10.1186/s12889-015-2385-y

[54] Laumann, E.O. and Mahay, J. (2002) The Social Organization of Women's Sexuality, In: Wingood, G.M. and DiClemente, R.J., Eds., Handbook of Women's Sexual and Reproductive Health, Springer Science \& Business Media, New York, 43-70. https://doi.org/10.1007/978-1-4615-0689-8_4

[55] Zhang, N., Parish, W.L., Huang, Y. and Pan, S. (2012) Sexual Infidelity in China: Prevalence and Gender-Specific Correlates. Archives of Sexual Behavior, 41, 861873. https://doi.org/10.1007/s10508-012-9930-x

[56] Schwarz, E.R., Kapur, V., Bionat, S., Rastogi, S., Gupta, R. and Rosanio, S. (2008) The Prevalence and Clinical Relevance of Sexual Dysfunction in Women and Men with Chronic Heart Failure. International Journal of Impotence Research, 20, 85-91. https://doi.org/10.1038/sj.ijir.3901613

[57] Fisher, A.D., Bandini, E., Corona, G., et al. (2012) Stable Extramarital Affairs Are Breaking the Heart. International Journal of Andrology, 35, 11-17. https://doi.org/10.1111/j.1365-2605.2011.01176.x

[58] Herbenick, D., Reece, M., Schick, V., Sanders, S.A., Dodge, B. and Fortenberry, J.D. (2010) Sexual Behavior in the United States: Results from a National Probability Sample of Men and Women Ages 14-94. The Journal of Sexual Medicine, 7, 255 265. https://doi.org/10.1111/j.1743-6109.2010.02012.x

[59] Richters, J., de Visser, R.O., Badcock, P.B., et al. (2014) Masturbation, Paying for Sex, and Other Sexual Activities: The Second Australian Study of Health and Relationships. Sexual Health, 11, 461-471. https://doi.org/10.1071/SH14116

[60] Brody, S. (2006) Blood Pressure Reactivity to Stress Is Better for People Who Recently Had Penile-Vaginal Intercourse than for People Who Had Other or No Sexual Activity. Biological Psychology, 71, 214-222.

[61] Brody, S. and Costa, R.M. (2009) Satisfaction (Sexual, Life, Relationship, and Mental Health) Is Associated Directly with Penile-Vaginal Intercourse, But Inversely with Other Sexual Behavior Frequencies. The Journal of Sexual Medicine, 6, 1947-1954. https://doi.org/10.1111/j.1743-6109.2009.01303.x

[62] Ogoh, S. and Ainslie, P.N. (2009) Cerebral Blood Flow during Exercise: Mechanisms of Regulation. Journal of Applied Physiology, 107, 1370-1380. https://doi.org/10.1152/japplphysiol.00573.2009

[63] Ogoh, S., Washio, T., Sasaki, H., Petersen, L.G., Secher, N.H. and Sato, K. (2016) Coupling between Arterial and Venous Cerebral Blood Flow during Postural Change. American Journal of Physiology. Regulatory, Integrative and Comparative Physiology, 311, R1255-R1261. https://doi.org/10.1152/ajpregu.00325.2016

[64] Sato, K., Ogoh, S., Hirasawa, A., Oue, A. and Sadamoto, T. (2011) The Distribution of Blood Flow in the Carotid and Vertebral Arteries during Dynamic Exercise in Humans. Journal of Physiology, 589, 2847-2856. https://doi.org/10.1113/jphysiol.2010.204461

[65] Aksoy, D., Solmaz, V., Cevik, B., Gencten, Y., Erdemir, F. and Kurt, S.G. (2013) The Evaluation of Sexual Dysfunction in Male Patients with Migraine and Tension Type Headache. Journal of Headache and Pain, 14, 46. https://doi.org/10.1186/1129-2377-14-46

[66] Solmaz, V., Ceviz, A., Aksoy, D., et al. (2016) Sexual Dysfunction in Women with Migraine and Tension-Type Headaches. International Journal of Impotence Research, 28, 201-204. https://doi.org/10.1038/ijir.2016.22

[67] Eraslan, D., Yalınay Dikmen, P., Ilgaz Aydınlar, E. and Incesu, C. (2014) The Rela- 
tion of Sexual Function to Migraine-Related Disability, Depression and Anxiety in Patients with Migraine. Journal of Headache and Pain, 15, 32. https://doi.org/10.1186/1129-2377-15-32

[68] Wu, S.H., Chuang, E., Chuang, T.Y., et al. (2016) A Nationwide Population-Based Cohort Study of Migraine and Organic-Psychogenic Erectile Dysfunction. Medicine (Baltimore), 95, e3065. https://doi.org/10.1097/md.0000000000003065

[69] Amidu, N., Owiredu, W.K., Woode, E., Appiah, R., Quaye, L. and Gyasi-Sarpong, C.K. (2010) Sexual Dysfunction among Ghanaian Men Presenting with Various Medical Conditions. Reproductive Biology and Endocrinology, 8, 118. https://doi.org/10.1186/1477-7827-8-118

[70] Domínguez, E., Ruiz, L., Hernández, M.S., et al. (2015) Sexual Dysfunction in Migraine Patients Who Receive Preventive Treatment: Identification by Means of Two Screening Tests. Revista de Neurologia, 60, 10-16.

[71] Roth, R.S., Punch, M.R. and Bachman, J.E. (2011) Psychological Factors and Chronic Pelvic Pain in Women: A Comparative Study with Women with Chronic Migraine Headaches. Health Care for Women International, 32, 746-761. https://doi.org/10.1080/07399332.2011.555829

Submit or recommend next manuscript to SCIRP and we will provide best service for you:

Accepting pre-submission inquiries through Email, Facebook, LinkedIn, Twitter, etc. A wide selection of journals (inclusive of 9 subjects, more than 200 journals) Providing 24-hour high-quality service User-friendly online submission system Fair and swift peer-review system Efficient typesetting and proofreading procedure Display of the result of downloads and visits, as well as the number of cited articles Maximum dissemination of your research work

Submit your manuscript at: http://papersubmission.scirp.org/ Or contact asm@scirp.org 